\title{
Overcoming Network Overload and Redundancy in Interorganizational Networks: The Roles of Potential and Latent Ties
}

\author{
Francesca Mariotti, Rick Delbridge \\ Cardiff Business School, Cardiff University, Cardiff CF10 3EU, United Kingdom \\ \{francescamariotti14@gmail.com, delbridger@cardiff.ac.uk\}
}

\begin{abstract}
$T^{1}$ his paper builds on Granovetter's distinction between strong and weak ties [Granovetter, M. S. 1973. The strength of weak ties. Amer. J. Sociol. 78(6) 1360-1380] in order to respond to recent calls for a more dynamic and processual understanding of networks. The concepts of potential and latent tie are deductively identified, and their implications for understanding how and why networks emerge, evolve, and change are explored. A longitudinal empirical study conducted with companies operating in the European motorsport industry reveals that firms take strategic actions to search for potential ties and reactivate latent ties in order to solve problems of network redundancy and overload. Examples are given, and their characteristics are examined to provide theoretical elaboration of the relationship between the types of tie and network evolution. These conceptual and empirical insights move understanding of the managerial challenge of building effective networks beyond static structural contingency models of optimal network forms to highlight the processes and capabilities of dynamic relationship building and network development. In so doing, this paper highlights the interrelationship between search and redundancy and the scope for strategic action alongside path dependence and structural influences on network processes.
\end{abstract}

Key words: network evolution; interorganizational ties; network overload; redundancy; exploration; potential and latent ties

History: Published online in Articles in Advance May 17, 2011.

\section{Introduction}

There has been increasing interest in the nature of organizational network ties and their implications for knowledge creation and sharing (Ahuja 2000; McEvily and Zaheer 1999; Muthusamy and White 2005; Powell et al. 1996; Uzzi 1996, 1997). Research has suggested that close and dense networks characterized by embedded relationships (strong ties) facilitate the sharing of highly contextual and complex knowledge by developing trust and creating common values and norms (Dyer and Nobeoka 2000, Uzzi 1997). Dense networks are contrasted with sparse networks that are seen as less effective at transferring tacit and embedded knowledge, but they allow firms to avoid redundancy and find novel and heterogeneous forms of knowledge by relying on more distant and sporadic contacts (weak ties) (Burt 1992). A third stream of research recombines these conflicting views and recognizes the potential of network configurations that mesh cohesion and structural holes, strong and weak ties, and proximity and diversity (Levin and Cross 2004, Nooteboom 2000, Obstfeld 2005). Questions of how to efficiently manage networks remain, however, because the strengthening of network ties leads to increased redundancy (Maurer and Ebers 2006), whereas continuing to extend the network is costly in terms of search and can lead to network overload, i.e., the constraints faced by actors in managing and sustaining a large number of contacts (Steier and Greenwood 2000, Elfring and Hulsink 2007). Our understanding of how these challenges of network redundancy and overload may be overcome remains relatively limited.

Our primary focus in this paper is on interorganizational, dyadic relationships. A foundational concept for such research has been Granovetter's (1973) differentiation between strong and weak ties, which has informed numerous studies of networks' structural properties and their implications (e.g., Gulati 1995, Uzzi 1997). ${ }^{1}$ These constructs are critical to understanding network structures, but when treated as absolute and static in crosssectional analyses, they limit our ability to delineate the dynamic and multifaceted aspects of ties (Ibarra 1992) and to explain how networks may evolve. Specifically, current conceptualizations of network ties do not offer clear guidance on how firms may manage their networks in response to tie accumulation and the duplication of resources. As Steier and Greenwood (2000) have argued, network overload is particularly damaging in terms of efficiency because the positive effects of having a large number of contacts are cancelled out by the amount of extra time and resources needed to maintain them. Moreover, large networks may further exacerbate the problem of redundancy. In this paper we extend understanding of network evolution by providing a temporal 
and processual framing of how networks develop that moves beyond structural contingency models and revisits the limited attention paid to agency to date. This allows for an assessment of the processes through which networks develop as actors look for new opportunities and/or suspend exchange to overcome the related problems of redundancy and overload.

This paper contributes to our understanding of the issues involved in managing networks in dynamic environments, and in particular, how the twin problems of redundancy and overload can be overcome by exploring different forms of search activity, assessing processes of relationship formation and decay and the relevance of different types of ties for accessing and mobilizing new knowledge in a longitudinal empirical study of firms in the European motorsport industry. Specifically, this paper first extends theory on network ties by elaborating on the distinction between weak and strong ties. We deduce two further types of ties from past research-potential and latent ties. These are defined as, respectively, embryonic relationships where knowledge transfer has not yet occurred and established relationships that are currently inactive in terms of exchange. Such ties have been described (e.g., Todeva 2006), but not previously, to our knowledge, have they been formally defined and made the subject of empirical research. We then draw on empirical evidence to evaluate their significance in terms of how the network develops. For example, the active search for and development of new potential ties both offer firms the opportunity to identify new ideas (affecting the structure of the network) and also help engender a network context conducive to knowledge creation (promoting collaboration between network partners). Conversely, the decay of strong ties to a latent form alleviates redundancy and overload problems, but if revitalized, these ties may quickly become sources of newly relevant knowledge. Networks thus evolve through actors' looking at new opportunities (developing potential ties) and/or by suspending exchange with others that are redundant (maintaining latent ties). Such a formulation moves away from existing static conceptualizations of network ties and offers a better understanding of the nature and role of differing ties in high-tech and dynamic environments.

A second contribution comes from the close evaluation of firms' strategic actions in regard to these two types of ties. We elaborate understanding of how firms (i) promote or conduct search activities either through individuals or organizationally that extend beyond established connections or local fields to more distant potential collaborators, and (ii) respond to network redundancy by suspending exchange but maintaining latent relationships with established partners until circumstances create new opportunities or needs. This provides insights into how firms seek to build contingently optimal networks over time and with reference to current and future conditions through highlighting the significance of ongoing search and relationship managing processes.

A third contribution comes from the recognition and evaluation of the interrelationships between network development processes, knowledge requirements in innovation, and the strategic actions of firms. The strengthening of established ties leads to increasing network redundancy (Maurer and Ebers 2006), and to counteract this, firms temporarily suspend exchange but maintain these latent ties through informal and personal ties. Our findings show that motorsport companies prefer to renew past latent relationships rather than to forge new ties ex novo when these partners have shown expertise, high reliability, and quality of work. Moreover, given latent ties' history of successful exchange, their reactivation may provide a quicker and smoother way to handle new developments and emerging problems. Further research in different sectors is required, but our findings suggest that the maintenance of latent ties that can be reactivated may be a more efficient and effective way to cope with periods of network redundancy than extending proactive search activity.

The rest of this paper begins by providing some theoretical background to the notion of organizational network ties and their link to knowledge transfer. Building on and extending those ideas, it develops and defines potential and latent ties. It then describes the empirical setting and data sample. The empirical findings are presented to show how these types of ties inform processes of network development and to explore when and why such ties are most relevant. Finally, it presents and discusses the results, underlining the value of potential and latent ties in extending our understanding of processes of network evolution and how the problems of redundancy and overload may be overcome.

\section{Theoretical Background}

Theorizing on network ties has its roots in sociological theory and, in particular, the work of Granovetter (1973, 1985). His distinction between strong and weak ties has shed light on the nature of social attachments and the complex social elements that characterize them. Further research in this area has identified the key features of these ties in business networks (see Gulati 1995, Larson 1992, Ring and Van de Ven 1992). This literature portrays strong ties in terms of close-knit bonding, philos, and repeated and prolonged interactions among the parties (Krackhardt 1992; Uzzi 1997, 1999). It also highlights that this familiarity fosters high levels of trust, reciprocity, and social capital (Gulati 1995, Larson 1992, Nahapiet and Ghoshal 1998). For example, Dyer and Nobeoka (2000) describe how repeated and long-term interactions between Toyota and its suppliers have promoted the emergence of strong ties based on trust, norms of reciprocity, and social attachments. Weak ties, on the 
other hand, are characterized by irregular and infrequent exchanges without any extended social contact among the parties. Their short-lived nature, however, cannot be assumed. As Dyer and Singh (1998) have observed, weak relationships may involve frequent and enduring encounters. The defining distinction between strong and weak ties is the closeness (or what Marsden and Campbell 1984, p. 498, describe as "emotional intensity") informing the nature of action and transaction. This distinction, drawing on Parsons (1968), is sometimes described in terms of universalistic or particularistic relations (Biggart and Delbridge 2004).

Several scholars have also explored the implication of these ties for knowledge transfer activities across a variety of contexts (Faems et al. 2007; Hansen 1999; Uzzi 1996, 1997). What they conclude is that strong and weak ties offer contrasting benefits in terms of the knowledge flows they facilitate. Strong ties provide organizations with high-quality information and tacit knowledge and allow joint problem-solving arrangements to develop. Weak ties, on the other hand, act as bridges between separate actors and allow them to access novel information. It is thus common in the literature to see strong ties associated with knowledge exploitation and weak ties with exploration (see, for example, Nooteboom 2000).

In recent years a great deal of research has extended the above-mentioned arguments at the interorganizational level of analysis, investigating how network structures facilitate or hinder knowledge flows (Ahuja 2000; Burt 1992; McEvily and Zaheer 1999; Muthusamy and White 2005; Powell et al. 1996; Powell 1998; Tsai and Ghoshal 1998; Uzzi 1996, 1997). A key argument is that specific network positions confer advantages to organizations in terms of increased collaboration, better access to information about potential partners, exchange of tacit and complex knowledge, and development of trust. However, there has been disagreement both about the network configuration responsible for such benefits and the implications for organizations seeking to devise an optimal network of ties. Some scholars stress the positive effect of dense and close-knit relations among firms (Coleman 1988, Powell 1990) or "close networks" in the exchange of knowledge and the creation of group norms, trust, and embeddedness. However, structural holes theory (Burt 1992) argues that the benefits of network structures result from the diversity of information created by loose collections of firms. According to Burt, close networks hinder organizational performance by promoting increasing levels of redundancy. This argument has been substantiated by the work of Gargiulo and Benassi (1999), Uzzi (1996, 1997, 1999), and Uzzi and Gillespie (2002), who find that when organizations are overly dependent on embedded ties, they seal themselves off from external sources of new ideas.

Some have attempted to integrate these differing perspectives and have reached the conclusion that the optimal network structure in terms of knowledge transfer is represented by a mix of strong and weak ties (see Burt 2001, Uzzi 1997). Although the combination of these two perspectives has advanced our understanding of knowledge flows in network structures, there has been less work done on the problems of achieving efficient and effective networks. Obstfeld (2005, p. 103) captures an aspect of this with what he labels the "action problem." This refers to the fact that a network rich in structural holes offers substantial benefits in terms of exposure to a wide variety of ideas but at the same time limits effective action taking. Research has found that having a wide-ranging network of relationships both enhances firms' ability to find valuable knowledge and their speed of learning (McEvily and Zaheer 1999, Reagans and McEvily 2003, Zahra et al. 2000). Unless they subsequently develop in certain ways, however, these structures may not be able to implement those ideas in an effective way. A key problem for firms, in this respect, is the management of a large number of connections. In the long run, the sheer number of these may become damaging and erode the benefits offered by being connected to multiple parties, a situation described by Steier and Greenwood (2000, p. 168) as "network overload." For example, a study by Burt (2004) on the opportunities presented by structural holes clearly reveals the lack of activity directed at mobilizing and implementing novel ideas. Similarly, Owen-Smith and Powell (2003) find that patenting activity by U.S. universities working for the biotechnology industry is harmed by a very high volume of connections.

Close and dense networks, in contrast, are better able to bring about coordination and implementation activities and, thus, foster knowledge creation. However, their very structure hinders the generation of new ideas because of the redundancy of the information they gather (Granovetter 1973, Burt 1992). This problem seems to be particularly relevant in turbulent and fast-changing environments associated with technologyintensive sectors. In these circumstances, there is an increasing emphasis on strategic action, and firms must remain alert and constantly scan the market for new and alternative ideas (Afuah 2000, Ahuja 2000, Rowley et al. 2000). However, merely seeking to grow the network as a response to new needs runs the dual risk of redundancy and overloading the network. Relatively little is known about how firms can address these challenges, and recognition of these issues has heralded recent calls for greater attention to the processes of network formation and development and the role of strategic actors in these processes (Dhanaraj and Parkhe 2006, Parkhe et al. 2006).

Concerns to develop research on network processes, in general, and the action problem associated with both structural holes and close networks, in particular (Levin and Cross 2004, Obstfeld 2005), reflect the static manner in which network ties have been defined in the literature (Granovetter 1992, Ibarra 1992). Conceptualizations of 
ties have concentrated on whether they are (relatively) strong or weak. This remains useful but limits our understanding of the dynamics of ties. The network literature has paid little attention to the temporal characteristics of ties; in other words, ties are treated as if they are unaffected by time and history. This "temporal reductionism" (Granovetter 1992, p. 34) limits our understanding of how relationships change and transform over time, and it also restricts the understanding of the role of actors in network change (Salancik 1995, Parkhe et al. 2006). Although a number of studies have started to shed light on the phases through which relationships may continue or decline (Baker et al. 1998, Burt 2000b, Fichman and Levinthal 1991, Levinthal and Fichman 1988, Ring and van de Ven 1992, Seabright et al. 1992), their work remains anchored to the analysis of selected moments in the development of ties. In addition, this literature has given little consideration to the role of strategic action in how ties are built, how they strengthen or weaken over time, nor to how the problems resulting from network growth through tie accumulation can be overcome.

In this paper, we aim to address these questions of network management and efficiency and the processes and roles of actors involved by extending Granovetter's initial distinction and introducing the concepts of potential and latent ties. This provides a broader basis for understanding the processes leading to both the inception and changing nature of network ties over time. It also has important implications for how knowledge is both shared and created at the network level over periods of time. The following section provides definitions and a brief discussion of potential and latent ties and adds these to a typology of ties alongside strong and weak ties.

\section{Potential and Latent Ties}

Existing research gives little consideration to the exploration activities involved in the search for potential exchange partners and to the processes that lead to the development and strengthening of these relationships (Birkinshaw et al. 2007). Search activities will initiate links with numerous actors. We call these putative relationships potential ties, and we define them as embryonic relationships that have the opportunity of, and potential for, further development. Exchange is restricted to readily codified information about each other from which the parties decide whether to invest further in the relationship. This is thus a temporary condition from which a tie may further develop or die. The prospects of development depend upon the actors' "logics of attachment" (Powell et al. 2005, p. 1134)—preferential attachment according to degree (Barabási and Albert 1999, Watts and Strogatz 1998), where well-connected actors are more likely to receive new links; homophily (McPherson and Smith-Lovin 1987), whereby ties are more likely to develop between actors that are similar in certain characteristics; and trend following, where actors seek to mimic the dominant pattern of behaviour in an organizational field (DiMaggio and Powell 1983) and/or their orientations to exchange (Biggart and Delbridge 2004). They may also depend on partners' status, reliability, and ability to confer valuable resources (Gulati 1995, Gulati and Gargiulo 1999, Podolny 1994). Hence, over time these relationships may develop in a number of ways, with some ties becoming increasingly embedded. For example, the discovery of a promising opportunity to develop a new technology or a new process may encourage potential partners to come together and engage in joint R\&D activities. However, for such joint learning and knowledge creation to happen, the partner firms have to promote increasing levels of social interaction founded on the development of shared norms and procedures (Kogut and Zander 1996, Muthusamy and White 2005). This can also be achieved with the help of third parties who facilitate coordination between dissimilar others (Obstfeld 2005).

Ties may become weaker rather than stronger. As previously mentioned, this is a phenomenon in networks that has been noted but little investigated (Baker et al. 1998; Burt 2000a, b; Elfring and Hulsink 2007). The weakening of strong ties may lead to a state of latency. Latent ties are established relationships that are currently inactive. This, however, is not a permanent condition. Over time, the parties may reverse this state and reestablish meaningful interaction or what organizational theorists call "tie repetition" (Baum et al. 2005, Sorenson and Stuart 2001). Such a phenomenon has been observed in the context of project-based organizations. For example, Faulkner (1983), in his study of the movie industry, notes that even after the completion of a movie, parties often maintain latent relationships that are reactivated for subsequent projects. Similarly, Starkey et al. (2000, p. 300) have advanced the notion of "latent organization." This has also received attention in entrepreneurial studies. For example, Steier and Greenwood (2000), in their study of angel investors, describe the development of an entrepreneurial network through the reactivation of "dormant" ties. Latent relationships, because of their discontinuous activity, may bring nonredundant information to the network and alleviate excessive insularity. If latent ties remain inactive over long periods, then they may suffer further decay.

Drawing on past research and theory, we are thus able to differentiate ties on a series of dimensions: the character of the social relations between actors, including those actors' orientations to the exchange relationship and the regulation of the relationship; and their temporal dimensions - that is, their frequency of use and the length of the relationship. Latent and potential ties can then be compared with the well-established concepts of strong and weak tie (see Table 1). Strong and weak ties have been understood as both discrete categories and ends of a continuum in cross-sectional analyses, but the 
Mariotti and Delbridge: Overcoming Network Overload and Redundancy in Interorganizational Networks

Table 1 Typology of Network Ties

\begin{tabular}{|c|c|c|c|c|}
\hline & Strong tie & Weak tie & Potential tie & Latent tie \\
\hline Social relations & Particularistic & Universalistic & Currently universalistic & $\begin{array}{l}\text { Particularistic but currently } \\
\text { inactive }\end{array}$ \\
\hline $\begin{array}{l}\text { Orientation and } \\
\text { regulation of } \\
\text { relationships }\end{array}$ & $\begin{array}{l}\text { Mutual reciprocity, } \\
\text { trust, norms }\end{array}$ & Self-interest, contracts & $\begin{array}{l}\text { Mutual interest, currently } \\
\text { contractual }\end{array}$ & $\begin{array}{l}\text { Deferred reciprocity (may } \\
\text { be reactivated) }\end{array}$ \\
\hline $\begin{array}{l}\text { Frequency of } \\
\text { interaction }\end{array}$ & High & Varies & Low & Declined, low to none \\
\hline Length of relationship & Long term & Varies & Short term & Long term \\
\hline
\end{tabular}

introduction of a temporal dimension as part of longitudinal analyses allows the dynamics of networks to be better assessed. Potential and latent ties are temporary conditions, and their theorization opens up the prospect for understanding the stages of tie development.

These are relationships that are relevant at multiple levels of analysis. Our primary focus in this paper is on interorganizational ties, which are analytically distinct from, but related to, the personal ties of organizational members (for an early consideration of this, see Breiger 1974). In practical and empirical terms, it is important to evaluate the interrelationship between these (see, with particular reference to social capital, Inkpen and Tsang 2005). For example, the movement of key personnel in partner firms with a latent tie may herald terminal decline in the interorganizational relationship.

\section{Research Setting and Methodology}

\section{Industry Context}

The European motorsport industry was selected as a prime venue for examining the temporal dynamics of interorganizational ties and their effects on network evolution in a high-technology, knowledge-intensive sector. Over the last 20 years, the industry has gone through a period of transformation that has changed the way racing-car manufacturers relate with their suppliers and compete on the track. This is particularly true for Formula One, where teams have moved from a vertically integrated structure to more organic and participative relationships with supplier companies. This change was in response to the growing complexity of the technology used in racing cars and increasing competition on the track (Jenkins and Floyd 2001). For example, improved knowledge of aerodynamics fuelled a range of technological developments that made the structures of cars more complex and elaborate. At the same time, the introduction of new materials from the aerospace industry required knowledge of their properties. Hence, the design and building of racing cars became more demanding and involved specialized know-how that racing teams did not have. This required racing-car manufacturers to seek closer collaboration with key suppliers, becoming increasingly reliant on their contributions for the development of innovations, components, and testing. It also led to changes in the nature of relationships. Racing-car manufacturers vertically disintegrated, changed procurement strategies, and actively encouraged increased collaboration with supplier firms.

Technological development brought with it an increase in the levels of competition. Racing teams compete in the search and development of technical solutions that will give them an advantage on the track. This means that teams dedicate a considerable amount of time and money to R\&D, identifying the best suppliers and developing relationships with them. Competition for the best solutions is then translated into competition on the track.

\section{Methods}

This paper is based on a qualitative and longitudinal project. Research was conducted between January 2001 and April 2002, with a second period of interviewing between September 2004 and February 2008. The collection of data over time was further enriched with the inclusion of retrospective questions with the aim of ascertaining the nature of interorganizational connections and their dynamics. Specifically, the first wave of interviews took into consideration how racing-car manufacturers organize their product development activities across their boundaries, the nature of the relationships they establish with supplier companies, and their changing knowledge needs. The second wave of interviews went one step further into understanding how network relationships changed over time and what choices were made by racing-car manufacturers in managing their relationships with suppliers.

The key players examined are racing-car manufacturers and suppliers of components and services. The networks are diverse, and suppliers have been classified by looking at the activities they carry out and the capabilities they have. Initial information about the range of activities performed in the motorsport industry was obtained from the Autosport directory (Pye 2001). Further clarification of the roles and activities of supplier companies was gained through the interviews, and the following types of suppliers were identified: commodity supplier, process specialist, equipment specialist, production specialist, technology specialist, full-system 
Table 2 Typology of Supplier Companies in the European Motorsport Industry

\begin{tabular}{|c|c|c|}
\hline Type of supplier & Type of components & Nature of the work performed \\
\hline Commodity supplier & Low-cost catalogue items & $\begin{array}{l}\text { Product design and } \\
\text { manufacturing }\end{array}$ \\
\hline Process specialist & Relatively complex processes & $\begin{array}{l}\text { Treatments and finishing of } \\
\text { components }\end{array}$ \\
\hline Equipment specialist & Relatively complex products & $\begin{array}{l}\text { Design and manufacturing of } \\
\text { equipment }\end{array}$ \\
\hline Production specialist & $\begin{array}{l}\text { Relatively complex parts. The } \\
\text { racing-car manufacturer knows } \\
\text { the specifications in detail }\end{array}$ & Manufacturing and finishing \\
\hline Technology specialist & $\begin{array}{l}\text { Complex parts. The supplier } \\
\text { retains the specialist knowledge }\end{array}$ & $\begin{array}{l}\text { Product and process design, } \\
\text { manufacturing and finishing }\end{array}$ \\
\hline Full-systems supplier & $\begin{array}{l}\text { Complex systems. The supplier } \\
\text { retains the specialist knowledge }\end{array}$ & $\begin{array}{l}\text { Product and process design, } \\
\text { manufacturing and finishing }\end{array}$ \\
\hline Technology partner & $\begin{array}{l}\text { Complex parts with innovative } \\
\text { application }\end{array}$ & $\begin{array}{l}\text { Product and process design } \\
\text { manufacturing and finishing }\end{array}$ \\
\hline
\end{tabular}

supplier, and technology partner. These are not mutually exclusive categories, because one supplier may assume different roles for different customers or products; e.g., full-systems suppliers may also be technology partners. This typology represents an increasing level of technological complexity (see Table 2). The full range of suppliers is included in the research.

A total of 37 companies were included (21 in the United Kingdom and 16 in Italy) in the first phase of interviewing using the technique of purposeful sampling (Patton 1990). These samples were subsequently extended to include an additional 39 companies to the project (26 in the United Kingdom, 5 in Italy, 5 in Germany, and 3 in France). Expanding the sample was motivated both by the opportunity to follow up specific examples of interorganizational relationships from the first phase and by the possibility of collecting information about multiple partners located in different European countries. This allowed us to obtain maximum variation (Lincoln and Guba 1985) and to select companies that were performing different tasks and were also related to other industries (e.g., aerospace, chemical, metal treatments). Analysis of historical data indicates the increasing tendency of racing-car manufacturers, especially in Formula One racing, to create linkages with actors operating in lateral fields of technology that may provide complementary knowledge and ideas.

In total, 114 interviews were carried out, with 59 taking place during phase 1 and 55 in phase 2. The UK industry has a larger number of firms involved in motorsport, and the majority of interviews were carried out there (69). Interviews were held with people at different organizational levels and performing different tasks. In particular, three categories of people were chosen: directors and managers, engineers (mainly in the area of product development), and other employees from the production/technical division responsible for production. This allowed the authors to gain a multilevel understanding of the nature and quality of ties, search activities, and knowledge flows. Whereas interviews with directors and managers helped to better understand issues regarding the management of relationships, those with engineers and technical staff were aimed at finding out why and how motorsport companies search for new technologies and knowledge and how these contribute to knowledge creation. All of the interviews were conducted by one of the authors and then discussed jointly soon after. The interviews lasted from 45 minutes to over 2 hours in length and were conducted on a one-to-one basis with participants either in their private offices or in a meeting room.

The reporting of the interviews was made anonymous. The objective of the in-depth interviews was to unveil and elucidate the rich experience and knowledge of the respondents in relation to the nature of network ties established by motorsport companies. Particular attention was given to the general reflections, experiences, and insights of the respondents in connection with the initiation, strengthening, and weakening of relationships. All of the interviews were taped and transcribed verbatimand those in Italian were translated into English. Some time was also spent talking to participants informally, usually joining them for lunch or coffee, and records were also made of these discussions.

Data collection and analysis were conducted with an exploratory mind-set, and they were intended to generate insights into the types and nature of the connections between racing-car manufacturers and their suppliers in relation to knowledge sharing and creation. The process of data collection and analysis proceeded iteratively. In the early stages, it was open-ended, and it became more focused in the later stages to allow for themes to emerge and then be explored and examined in more detail. For example, whereas at the beginning respondents were asked whether they were engaging in knowledge search 
activities, at later stages they were also asked to provide specific information on how different search processes were handled. This became an important issue because motorsport companies search for new information in different ways. The initial phase focused on gaining an understanding of company activities and their connections within the industry. In the later stages of the research, interviews became more focused on specific topics, and emergent themes were followed up. In particular, these related to issues of relationship formation and decay, as well as the importance of network diversity.

In addition to interviews and observation, extensive documentation about the companies, their projects, their partners, and the motorsport industry was collected. This provided important contextual information that helped in framing the nature of ties in the industry and their contribution to knowledge creation activities.

Inductive qualitative analysis techniques were used to analyze the data (Coffey and Atkinson 1996, Eisenhardt 1989, Strauss and Corbin 1990). Analysis consisted of several readings of the interview transcripts, and various documentation, and a review of the issues emerged during the informal conversations with participants. This generated a number of general categories that were subsequently refined through constant comparison of the data. The categories that emerged included the following: "close/weak interaction," "joint work," "new relationship," "relationship with no exchange," "complex technology," and "problem solving." The progression from data collection to interpretation was intended to be reflexive rather than serial. Although there was an effort to verify the findings of previous research (Eisenhardt 1989), that focus alone would have precluded important emergent understandings about the nature of potential and latent ties and their relevance for knowledge creation and transfer. Moving reflexively between data, analysis and reconceptualizations allowed categories to be compared and combined in new ways until a general picture started to emerge.

\section{Network Ties in the European Motorsport Industry}

Motorsport companies in the European motorsport industry draw extensively on strong ties. These are developed over time, often as a result of the heightened competition and the growing technological complexity in the industry. The empirical findings show how racingcar manufacturers have put more effort into developing closer business relationships with their suppliers than was historically the case. This has been achieved through vertical disintegration and the involvement of suppliers in the early stages of product development. By encouraging suppliers to participate collaboratively in product development activities, racing-car manufacturers have then sought to progressively nurture a network orientation toward "working together."

In this context, both personal and organizational ties play an important role because the industry is relatively concentrated and composed of many small- and medium-sized firms. Relationships at the interorganizational level are often enhanced by the development of interpersonal linkages as a way to facilitate knowledge exchange, especially when the complexity of the technology involved requires numerous skills and functions. The use of resident engineers, where employees of one organization are located at the site of another, is a good example of how racing-car manufacturers and suppliers progressively develop multiple personal relationships that further strengthen interorganizational linkages and build stronger embedded ties. This in turn provides the foundation for ongoing face-to-face interaction and sharing of knowledge. As we will see, personal ties also feature prominently in search activities and may prefigure interorganizational relationships.

Although racing-car manufacturers make significant efforts to develop strong ties, their endurance cannot be guaranteed. The continuation of collaborative relationships is often informed by the perceived needs and strategy of racing-car manufacturers. Specifically, decisions relating to the further strengthening of ties or the termination of exchange will be influenced by each partners' reputation and reliability and each racing-car manufacturers' orientation to exchange and resource requirements. The existence of weak or weakening relationships seems to be directly related to the presence of exiguous or nonexistent specific investments in a relationship (Williamson 1985). When the knowledge and the resources exchanged are of modest value or concern readily available information, then the relationship will be unlikely to strengthen. As shown by Hansen (1999), weak ties can be a source of useful information but do not involve the high maintenance costs associated with close and strong ties. This is specifically the case of companies providing interchangeable components or those who provide low-tech components/services. Thus, supplier companies providing relatively generic products or services, or those with numerous competitors, find it difficult to build close relationships. The relative ease with which they may be substituted leaves them with limited influence and power, as anticipated in well-established resource dependence arguments (Pfeffer and Salancik 1978). This is particularly the case in the United Kingdom, which is home to numerous race teams and suppliers.

Tie dynamics and the nature of the exchanges taking place are affected in a significant way by key actors' strategic considerations and actions. The weakening of relationships shows how racing-car manufacturers are selective and vary the extent to which they develop closer links. This will depend on their assessment of 
the reliability of suppliers and the value and scarcity of the knowledge and resources they are able to offer. The extent of involvement and investment in a weak relationship will also influence whether ties are shortterm links or durable arm's-length relationships (see Dyer et al. 1998).

\section{Searching for Potential}

Strategic considerations shape not only current ties but also inform whether new exchange relationships are formed (potential ties) or existing exchange is suspended (latent ties). The search for potential new partners and new sources of knowledge/solutions is driven by the technological complexity of the knowledge required in motorsport, its rapid obsolescence, and the consequent need to anticipate future technology needs. As the head of engine development of GE-F1 proclaimed, "We cannot allow other companies to introduce new technologies before us; we have always to be in contact with the latest developments in engine technology." Hence, in this highly competitive environment, motorsport companies have to constantly look for new technological possibilities with the concomitant prospect of needing to expand their network ties. Although theory predicts that past choices and ties affect subsequent affiliations by promoting tie repetition or tie transitivity, motorsport companies show a significant degree of strategic choice. In particular, they display a preference for diversity (Powell et al. 2005), searching for novelty in different engineering fields and connecting to heterogeneous partners. The search for new partners and potential new ideas is not always straightforward, and it can take a variety of forms. Our research identified four related search activities: search by individuals through personal ties, search by individuals through professional work ties, informal open-ended search by individuals, and formal strategic search by organizations (see Table 3 ).

In some cases, motorsport companies draw on engineers' past personal ties as a way to get in contact with new partners. These personal ties originate either from engineers' friendships and past education contacts or from their previous employment. In a relatively small and concentrated sector like motorsport, these are a significant potential resource and constitute an important base for the forging of new interorganizational ties between companies that do not have current business relationships. This is because personal ties reduce the uncertainty about potential partners and provide quicker

Table 3 Forms of Search Activity

Search for new potential ties Example

Through personal relationships

"I have a very old friend, one of my old associates, one of the first jobs that I was ever involved in motorsport, which was back in 1984; he was the design... one of the design managers for the racing company that I worked for. Well I contacted him about two years ago when I knew he was at the race team, and I wanted... because they weren't using our product at the time and because he was high up in the organization... usually if you know somebody and you have something, you're better able to talk to someone who knows you, who will listen to you." (Managing director, technology specialist supplier)

"To develop this technology we made contact with [supplier name]. One of our staff had a personal relationship there with an engineer who was familiar with some of the materials and processes we wanted to use. Therefore, we decided to develop the relationship with the supplier and start collaborating on the project." (Head of materials development, GE-F1)

Through work-related relationships

Informal search activities (through participation at trade fairs, exhibitions, and conventions in different technological fields) Strategic search activities
"There's another guy that used to work for one F1 team who was high up in the design; he's now gone to work for a rally team within WRC, the World Rally Championship; he's one of the major design engineers. I contacted him; initially he seemed very interested, spoke with him for some length on the phone and he made, well, I would say he made the right sounds and noises, and I thought, yeah, great, next year we can do some development work. Six months went by, eight months went by; I managed to get a response from him which wasn't what I wanted to hear and then I got another response back from him which was totally what I didn't want to hear, that basically said we'll contact you, we know where you are, we'll contact you." (Managing director, technology specialist supplier)

"They all have what we call a day job and then in the evenings myself and some of my colleagues will go to technical seminars, we will go and visit universities; you know they often see new things coming through or they have new ideas." (Engineering director, full-system supplier)

"We have technological antennas which we send to trade fairs, workshops, and exhibitions in different fields of technology to check what is new on the market or to search for new suppliers. They are people who have a longstanding experience in F1 and who have maybe worked for other F1 teams or who have a close relationship with specific suppliers. They also have a deep knowledge of how we work and what are our technology requirements." (Head of car performance and research and development, Italy-F1a) 
and easier access into resources and knowledge. These ties are often developed reactively in response to a problem that emerges.

More proactive and strategic search activity may be undertaken by individuals or at organizational levels. Individual employees' attendance at trade fairs, exhibitions, and workshops in different fields of engineering is another way through which motorsport companies may come into contact with new technology solutions and potential new partners. Sorenson and Stuart (2008) have observed that particular social settings favor the formation of distant ties, and Shipilov and Li (2012) have shown how individuals can enhance their career prospects through new interpersonal ties formed at informal events. These encounters, however, are largely serendipitous, and attendance at these events does not guarantee that new partners with high potential are found. A further and more strategic approach by motorsport companies to search for new partners is the use of individuals who act as "technological gatekeepers" (Allen 1977, p. 150). Technological gatekeepers search for, carry, and disseminate useful information. More specifically, their role is to scan the market in search of new technologies that could reside either with potential new partners or dormant relationships which have not been in use for some time. This case is exemplified by a leading racing-car manufacturer in Italy, which, over the last 10 years, has deliberately put in place "technological antennas" as a way to reach new ideas and act as "informative links" with suppliers or research centres. The use of technological antennas represents the strategic action of an organization in managing its network of ties. Whereas other motorsport companies tend to use an undifferentiated strategy to search and regard it as a secondary job of all employees, the Italian racing-car manufacturer has delegated the search function to various specialized groups of people to make it more effective and increase the variety of ideas flowing in the network. A German F1 racing-car manufacturer has also followed a similar approach and has put in place a number of research groups in various parts of the world to gain access to new technological developments and monitor different marketplaces and sectors.

These search activities bring individuals and organizations into contact with potential partners. Potential ties, as described previously, are relationships that are still embryonic but display the opportunity for development. The prospects for development of these ties, and the organizational decision to form and develop an interorganizational tie, depend on a number of features that are largely consistent with the extant literature on new tie formation. In general terms, motorsport companies tend to enter into a new relationship with other organizations that share a similar operational approach and context and/or display an interest in codevelopment. Motorsport companies also tend to form new ties with other companies that are leaders in a particular technological field or have a proven track record of working with other motor-racing companies. Relationships at interorganizational levels are also more likely to form between firms that have larger numbers of individual members with higher levels of interaction on a personal basis. This suggests that although motorsport companies have an espoused strategic preference for diversity in their connections, their actions are moderated (but not determined) by homophily, status, and path dependence influences.

The process of selection of potential new ties involves basic information exchange to assess the quality, similarity, orientation to collaboration, and resources of a possible partner. Third parties and common parties may also contribute to the collection of this essential information and help in the assessment process. This preliminary contact and flow of information form the basis for the possible development of potential ties into weak ties and then strong ties. Alternatively, if the parties conclude that the collaboration is not fruitful, their relationship will not develop beyond a weak tie and over time may well dissolve. This makes the search for relevant partners more efficient and helps motorsport companies avoid building a large array of contacts with its attendant difficulties. The evidence from the research on the actions taken in how potential ties start, may further develop, or decay is schematically represented in Figure 1.

The following two examples provide empirical evidence about the processes and actions that may lead to the development of potential new ties in order to briefly illustrate and elaborate these. The first example is the relatively straightforward case of a full-systems supplier seeking out new information about casting technologies and processes that was then used to inform investment in its own network's casting facilities. The commercial manager gives an account of the activities undertaken:

We started with a plain sheet of paper and we did a tour of the world to see what [casting] technologies are out there and we went to many different companies, and we brought back those ideas... and we put all the package together in a state of the art foundry that [supplier name] owns but our supplier-partner runs for us.... We developed better tooling practices, we develop better metallurgy and the casting process, and we believe we have made a significant step forward in castings by collaborating with a major supplier and a significant investment in the plant

In this case, the search process highlighted potential, but most of the potential ties identified did not develop beyond a limited exchange of publicly available information. Only subsequent processes of evaluation and interaction allowed a productive strong tie to emerge. The full-system supplier would not have been able to implement the knowledge gained without the help of a new expert partner capable of running the foundry. Thus, 
Figure 1 Action and Tie Developments: Building from Potential

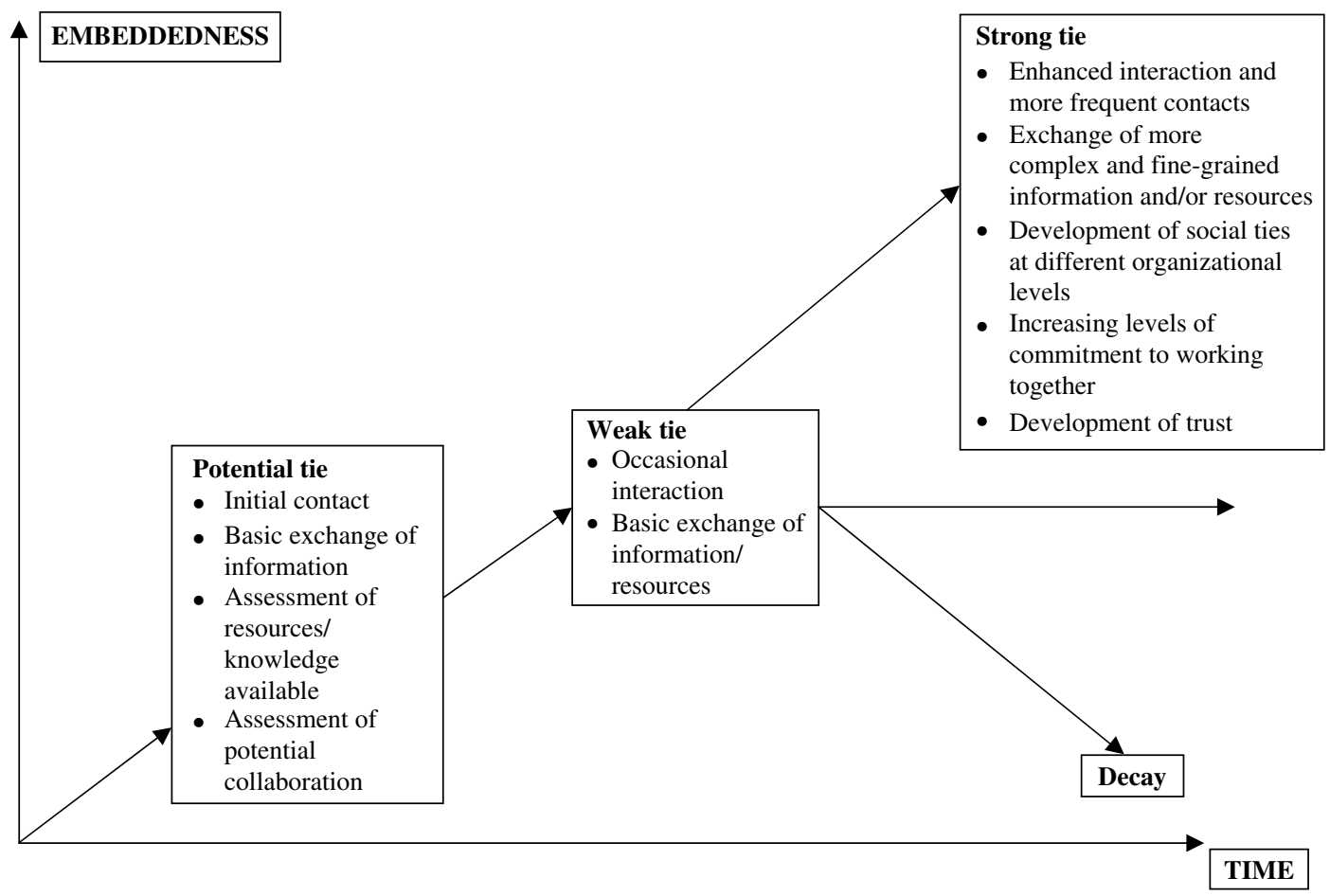

one of the potential ties identified in this search activity was further developed and strengthened to build a closer and more active relationship. This partner already had some knowledge of casting, but the information gathered through the tour allowed the two companies jointly to improve tooling, metallurgy, and casting processes significantly. The result was, for the two organizations involved, significant innovation in manufacturing processes, which in turn contributed to new product development. As anticipated by Obstfeld (2005), it is thus the combination of information gained and the action taken that results in the mobilization of knowledge and significant innovation.

A second example portrays the discovery of a technology specialist company with extensive knowledge in casting processes and how the development of this potential tie has led to a breakthrough development in technology. A small Italian supplier in collaboration with an Italian Formula One team (Italy-F1b) made a significant breakthrough in the processing of titanium for transmission components by casting rather than welding the metal. Because the Formula One team and its supplier lacked the necessary knowledge in casting to perfect their method, they engaged in search activities and looked for possible solutions in various sectors around the world. After trying many foundries, they found one in the United States that had specialist expertise in golf club manufacture, and they developed a collaborative link. The production manager of Italy-F1b presents a vivid account of the particular efforts made. He says,

The transmission in titanium is not something new. Barnard, together with Ferrari, was the first to introduce the transmission in titanium made of small pieces welded together. We have been the first to adopt the casting of titanium and this had a positive effect on the company; moreover, it has given visibility to the idea we developed with [supplier name]. [Supplier name] has done a lot of research in the production technology and in the casting technology - this is the biggest problem because of the thinness of the components required in Formula One; our transmission is very thin and to weld titanium parts in such small dimensions it is not easy. Instead of using moulds made of wood, they [the supplier] have refined a method called "micro-fusion" through the use of rapid prototyping; thanks to rapid prototyping, they have made the moulds for the casting and then they have started to look for a partner in the [United] States, helping them in the casting process. After trying many foundries, they found one-I think it is specialized in golf clubs, because the head of a golf club is hollow inside and requires being very thin-and together with this foundry, they have worked on the casting process.

Collaboration between Italy-F1b, the Italian supplier, and the American company started with some research on materials such as aluminium, steel, and titanium. The newly formed relationship took on a personal and social dimension as the parties became better acquainted and learned about each other. It then further progressed and deepened when the partners realized the potential for 
developing a specific process for the casting of titanium. This required intense and face-to-face collaboration because of the complexity of the problem and the uniqueness and tacitness of the knowledge involved. This engagement led to two further developments. First, it resulted in the emergence of norms regarding issues such as confidentiality, disclosure of information to external parties, trust, mutuality, and reciprocity. Second, it encouraged Italy-F1b, through its Italian supplier, to form a long-term partnership with the American company and to engage in the advancement of casting techniques and materials. Participation in joint development activities led to the innovative method for the casting of titanium, and a tie with initial potential developed and strengthened over a period of time.

Taking a wider view of the data, the findings indicate that motorsport companies, by engaging in the search for new partners, are able to garner a variety of ideas, solutions, and ways of thinking. The development and strengthening of these potential ties allow for those ideas and solutions to be implemented, stimulating innovation and knowledge creation (Table 4). The prospects for potential ties to develop into strong ties are much greater where prospective partners fulfill requirements of quality, similarity, and compatible orientations to exchange, and they are able to offer valuable resources and knowledge. Conversely, if these requirements are not met, then potential ties will at best develop into weak ties and over time are likely to decay. In this way, motorsport companies attempt to avoid excessive tie accumulation and make the search for relevant ties more efficient.

\section{Redundancy and Latency}

This consideration of search and potential ties highlights the interrelated evolution of individual ties, knowledge flows, and the wider network. An indirect consequence of companies' quests for new technological know-how and new ties is "redundancy," a key factor in the weakening of relationships. Redundancy represents the duplication of resources and knowledge and the reduction in relevance of the knowledge obtained from existing ties. In such circumstances, exchange with current ties that become redundant may be at least temporarily suspended. It is this feature of network dynamics that our second type of tie, latent relationships, helps to elaborate. Although these ties are dormant, they are still part of the network, primarily through the endurance of personal and informal ties. Over time, with new industry needs or through strategic developments on the part of firms, these relationships may be reactivated and revert into strong ties. The reinvigoration of these ties, however, often involves a redefinition of the terms of the collaboration in line with changing requirements. The findings indicate that latent ties may remain important to motorsport companies, and their endurance guarantees that valuable connections to resources and knowledge are not lost. Moreover, latent ties may subsequently become centres of newly relevant knowledge (at least from the point of view of the company who suspended the exchange). In these circumstances, latent ties become sources of novel ideas and knowledge. However, the persistence of redundancy, coupled with the disappearance of personal ties and minimal development in the content of the exchange, may signal the decay of the relationship. The empirical evidence on actions

\section{Table 4 Selection and Development of Potential Ties}

Factors influencing potential tie Example
development

Similarity of work environment and methodologies of work

Shared strategic (innovation) agenda

Leadership in a particular technological field outside motorsport

Proven ability to work successfully with other motorsport companies
"New ideas come about through contaminations with different environments. For this reason we have established a working relationship with [supplier name], an aerospace supplier. We are similar in many respects, for example, in terms of advanced technological research and in dealing with complex or difficult environments. We are constantly looking for this sort of relationship, but they are not premeditated." (Head of car performance and research and development, Italy-F1a)

"In many cases if you identify the right target, the chance of them saying yes is quite high, cos they are probably also a company that wants to push the frontiers. An example would be an American company, they haven't had much involvement with F1 teams before, but the way that the relationships tend to develop is we say, we have got this need, have you got any needs which match or can work together, you come and see us, we go and see you, and we get the technical experts together and see if there is anything there that kind of jells." (CEO, UK-F1)

"Their [supplier] relationship with us is based on them being able to develop processes with us that they then can showcase or utilize elsewhere in their client base: [supplier name] want to develop a relationship with us because they can demonstrate that they can do things for an F1 team in a very technical, difficult environment which then they can use elsewhere." (CEO, UK-F1)

"In the past, we [Ge-LeMans] successfully collaborated with [supplier name] a well-known supplier in motor racing on the direct injection TFSI used in the successful [Ge-LeMans car]. This collaboration has been carried over to the TDI project. Together we developed the latest generation of Common Rail Injection System." (Head of Design, Ge-LeMans) 
Figure 2 Action and Tie Developments: Intermediate Latency

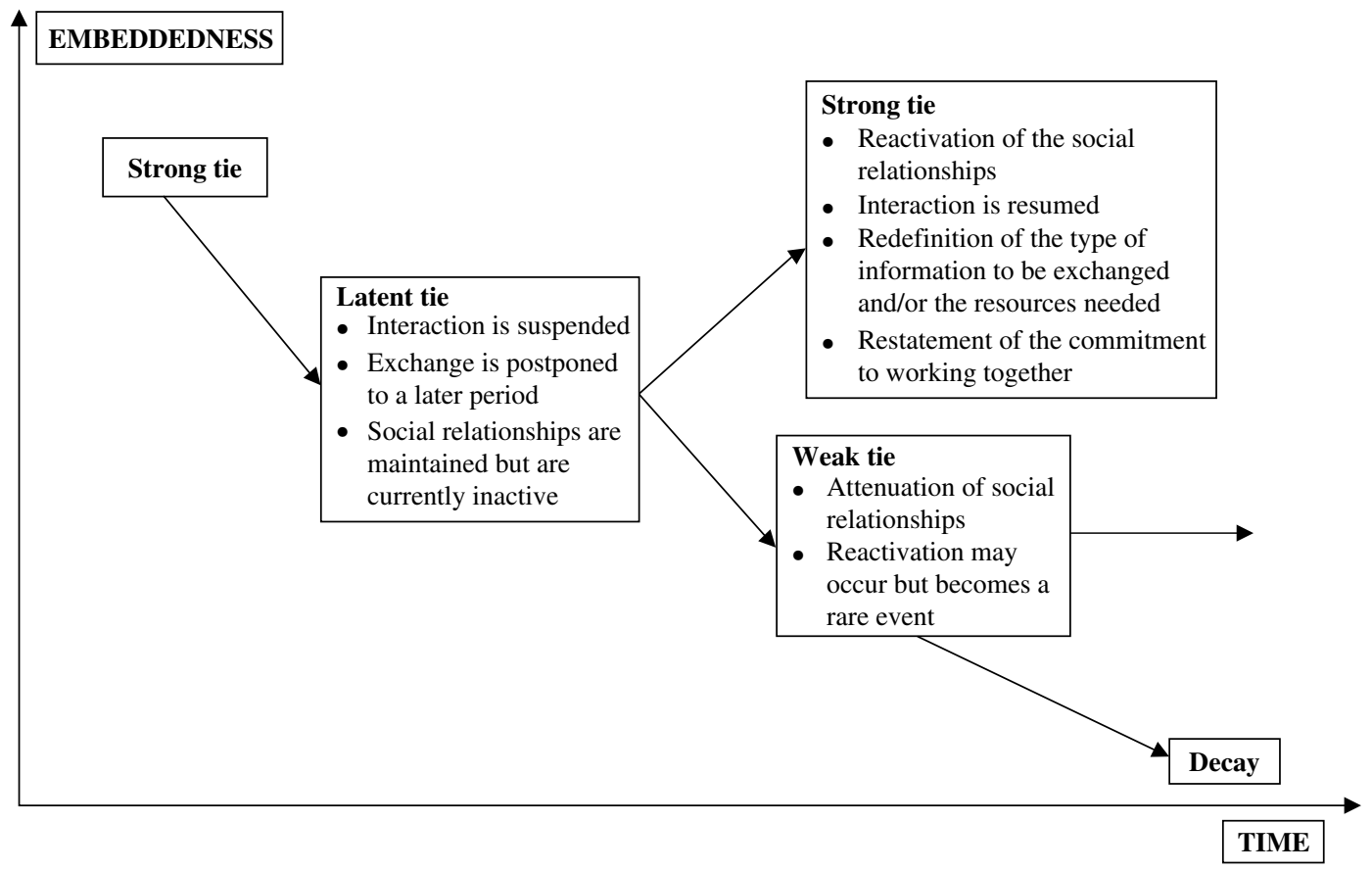

related to latency in ties is summarized schematically in Figure 2.

Two specific examples will elaborate how introducing the notion of latency in ties helps us understand redundancy and network dynamics. The first focuses on the problem-solving activities undertaken by a technology specialist company in the United Kingdom in relation to extrusion technology and the decline in the relevance of knowledge supplied by newly formed strong ties.

Given the complexity of extrusions, the UK supplier company had to engage in extensive search activities to locate new partners capable of helping in the advancement of the technology through their unique and tacit knowledge. The identification of two technically capable companies, however, was not enough, and the supplier company needed to develop and strengthen relationships in order to benefit from their unique experience and obtain customized knowledge. Joint experimentation and work took place for a number of years but was ultimately stifled by the inability of the two extrusion companies to achieve the desired results (one in technical terms and the other operationally) and hence contribute to the solution of this complex technical problem. This example empirically demonstrates Obstfeld's (2005) action problem whereby a source of useful knowledge was identified but could not be successfully mobilized. This led the supplier company to suspend any exchange and maintain the two relationships in a latent state as future development work could prove successful. The business manager elaborates on this point:
We will have made hundreds of samples to try and find ways of creating different angles and from that we will have developed these hollow sections, because where that mismatch in the shape is there, instead of that now we have that hollow section. But those hollow sections...there are very few people in the world that can produce a hollow section out of aluminium in that sort of shape. There's one company in Holland that told us they could do it, and they've been trying to do it now for three years and still can't do it, they've not been successful and we've found one company in America who have been reasonably successful and certainly for the last six years that's the company that we've been using. The difficulty we have with them is that because they're the only people that's proven they can do that extrusion for us in all the different shapes and thicknesses we need, they've become so successful they now can't cope with the work and they're not expanding fast enough, so the lead time for that extrusion has gone up from 3 weeks to now they're quoting us 10 weeks lead time, which is very, very slow.

Although the supplier company was able to come up with an alternative solution to this complex technical problem, the maintenance of latent ties with the two extrusion companies was motivated by the specific investments in research and development jointly undertaken and the lack of alternative sources of technical knowledge. As the business manager pointed out, the solution developed in-house allowed the company to keep on with its tight deadlines, but it proved to be much more expensive and less innovative. The inadequacy of this situation (in technical and cost terms) meant the 
company retained at least a latent connection to the two aluminium extruders.

A further example shows how a German racing-car manufacturer racing in the Le Mans series (Ge-LeMans) has managed a number of latent connections and their subsequent reactivation for the completion of a complex and difficult project involving the introduction of diesel engine technology into racing. In this case, the maintenance of latent ties superseded the alternative of adding extra new potential ties.

Ge-LeMans has worked for many years with a selected group of proven partners. Relationships, however, have been intense and active only during the implementation of major technical developments, whereas at other times they have been kept dormant. The retention of these ties was motivated by the fact that these suppliers were leaders in their field of expertise and over the years displayed a proven ability to work under the immense pressures and the tight time frames required at points in motor racing. Specifically, the German car manufacturer managed these latent connections by fostering the development of informal relationships at the individual level and by providing the partners with dedicated engineers who would constantly liaise both during and outside codevelopment activities. The presence and endurance of these informal relationships, coupled with the established norms of interaction, have allowed the German racing-car manufacturer to preserve these latent connections in a state of operational near-readiness. The racing-car manufacturer took the decision to concentrate on existing connections rather than expanding the network, thus avoiding the time and expense of search and the problems of establishing and managing new relationships.

The reactivation of these relationships, as in the case of the development of a diesel engine for the Le Mans series in 2003, was prompted by Ge-LeMans and promoted through a series of multiway discussions and meetings to discuss the feasibility of the project. The decision to renew the collaboration with past partners rather than to forge new ties ex novo was made because of the reliability of those partners, the quality of their previous work, and the unique knowledge they were able to bring to the project. Moreover, having worked on past projects, they were judged to be better able to understand the racing-car manufacturer's requirements and to respond to unforeseen circumstances compared to prospective new partners. The head of engine development at Ge-LeMans recounts the events:

When the idea for the project came up, my first job was to talk to them [suppliers] to give them an idea of what we wanted to make and what they are expected to do and to ask whether they are prepared to follow us and what is their opinion about that. At the beginning they wouldn't say it was impossible, but pretty close to it. But I dedicated time to explain the project to them and ask whether they would follow us-no matter how difficult it would have been to achieve that. And the commitment was $100 \% \ldots$. In general, one or two engineers from [Ge-LeMans] are assigned to each of our partners to keep communication going. They work directly with the suppliers and have regular meetings with them to discuss plans of development, costs, problems, etc. This brings huge benefits because the understanding between the companies is much deeper and there is a greater chance to learn from each other.

Collaboration with the partners during this project, as in others, was quite intense and involved the codevelopment of specific components designed to fit in the diesel engine. The result of this collaboration was diesel engine technology that produced the first-ever purposebuilt diesel racing engine.

Moving beyond these specific examples, the evidence gathered in this study suggests that ties may remain latent, sometimes for considerable periods, but retain the possibility of reactivation. The successful renovation of the relationships and the reestablishment of collaboration, however, rest on three key factors. These are the presence of personal and informal individual-level ties, formally established routines and/or norms of interaction founded on past experiences of working together, and the quality of the partner in terms of its reputed expertise and reliability, particularly on the basis of past collaboration between partners. These features make the maintenance of latent ties both feasible and desirable. The empirical evidence supports the conceptualization of latent ties as formerly strong ties that are temporarily dormant; ties formed purely around the transfer of codified knowledge are unlikely to develop and are more likely to die out quite quickly once exchange ceases.

With regard to the questions of effectiveness and efficiency in networks, the evidence indicates that firms may prefer to maintain latent ties rather than engage in search activities and that they report the reactivation of these ties as both more efficient (in terms of time and resources) and more effective (in terms of innovation outcomes). Latent ties thus appear as a vital feature of motorsport networks and represent a key response on the part of firms to the challenges faced in dynamic environments.

Table 5 summarizes the key characteristics and formation features of each type of tie and relates these to knowledge creation and flows.

\section{Discussion and Future Research}

This paper addresses issues of network dynamics and evolution through an extension of the strong/weak tie distinction. It introduces potential and latent forms of interorganizational tie and empirically explores the processes of tie development and network management. A crucial question in understanding the development of efficient and effective networks is how firms can 
Table 5 Network Ties: Summary of the Findings

\begin{tabular}{|c|c|}
\hline NETWORK TIES & Description \\
\hline \multicolumn{2}{|l|}{ Strong ties } \\
\hline Characteristics & $\begin{array}{l}\text { Represent (and further promote) the development of close relationships, the establishment of interpersonal linkages, } \\
\text { and the sharing of specific knowledge and resources that are not publicly available. They can be costly to maintain } \\
\text { in terms of time and resources. }\end{array}$ \\
\hline Formation & $\begin{array}{l}\text { Interorganizational ties are developed over time through a progressive involvement of suppliers in the early stages } \\
\text { of product development and the creation of interpersonal linkages. In terms of strategic action, their formation } \\
\text { depends on the value and scarcity of the knowledge offered by suppliers and racing-car manufacturers' decision to } \\
\text { invest in a specific relationship. Formation is also influenced by issues of homophily and status. }\end{array}$ \\
\hline Problems & $\begin{array}{l}\text { Their presence generally leads to redundancy of knowledge/resources in the network over time. A large number is } \\
\text { expensive to maintain in terms of time and resources and may contribute to problems of network overload. }\end{array}$ \\
\hline Activity & $\begin{array}{l}\text { Provide firm-specific, complex knowledge, the underpinning basis for collaboration; and the prospect of } \\
\text { network-level knowledge creation. }\end{array}$ \\
\hline \multicolumn{2}{|l|}{ Weak ties } \\
\hline Characteristics & $\begin{array}{l}\text { Ties that can be used to provide resources and information that are readily codifiable and often relatively widely } \\
\text { available. They generally involve lower maintenance costs than strong ties. }\end{array}$ \\
\hline Formation & $\begin{array}{l}\text { They are represented by suppliers offering generic product/services that are widely available in the motorsport } \\
\text { industry and can be easily sourced. }\end{array}$ \\
\hline Problems & $\begin{array}{l}\text { They contribute to innovation and knowledge creation in a limited way unless they are developed further. When } \\
\text { excessive in number, they may generate network overload. }\end{array}$ \\
\hline Activity & Primarily provide codifiable information and fairly standard goods and services. \\
\hline \multicolumn{2}{|l|}{ Potential ties } \\
\hline Characteristics & $\begin{array}{l}\text { Embryonic ties that may be the source of new technologies or knowledge. Once a potentially valuable idea/piece of } \\
\text { knowledge is identified, potential ties can be further developed into strong ties. This is particularly the case for } \\
\text { those suppliers that can provide innovative and unique knowledge. }\end{array}$ \\
\hline Formation & $\begin{array}{l}\text { Involves both proactive searches for new knowledge developments and simple responses to technical problems. } \\
\text { They may be initiated by individuals who act as "technological gatekeepers" and search for, carry, and disseminate } \\
\text { information by operating in a wider context than the motorsport industry. They may also be formed through more } \\
\text { prosaic and serendipitous circumstances or by strategic organizational routines. }\end{array}$ \\
\hline Problems & $\begin{array}{l}\text { The relationship does not develop, new ideas are not necessarily implemented, and potential ties remain weak or } \\
\text { die. Developing the tie can require significant time and resources. }\end{array}$ \\
\hline Activity & $\begin{array}{l}\text { They are a source of new ideas and knowledge. If transfer takes place at an early weak-tie stage, or they are } \\
\text { developed into strong ties, they can stimulate innovation and knowledge creation. }\end{array}$ \\
\hline \multicolumn{2}{|l|}{ Latent ties } \\
\hline Characteristics & $\begin{array}{l}\text { Ties that have begun to provide redundant knowledge/resources; therefore, exchange is temporarily suspended. } \\
\text { These ties may be subsequently reactivated if they become sources of novel ideas and knowledge or } \\
\text { circumstances change to create new demands. }\end{array}$ \\
\hline Formation & $\begin{array}{l}\text { Typically, with suppliers whose products/resources have become less relevant. The reactivation of latent ties is likely } \\
\text { to be more straightforward and rapid than is the formation of new strong ties, because the partners have a history of } \\
\text { productive exchange. }\end{array}$ \\
\hline Problems & $\begin{array}{l}\text { Ties formed purely around the exchange of information/resources that have become widely available may further } \\
\text { decay. }\end{array}$ \\
\hline Activity & Little or no activity at the interorganizational level, unless ties are reactivated. \\
\hline
\end{tabular}

continue to ensure they have access to the resources that they need without succumbing to the redundancy and overembeddedness of dense networks, or the danger of overloading the network through continually seeking new weak ties. The research shows the importance of both proactive search activities as well as the identification of potential ties, and the managed latency of some (temporarily) redundant ties, in retaining and developing a network's access to novel ideas and the capability to mobilize new resources.
Our research makes three important contributions to current understanding of the challenges of managing networks. First, it extends current conceptualizations of network ties beyond the distinction between strong and weak and in doing so advances understanding of tie and network dynamics. Specifically, this paper introduces potential and latent ties and shows how these types of ties are important in explaining network development. Potential ties are new embryonic relationships that have the opportunity of, and potential for, further 
development, whereas latent ties are established strong ties that are currently dormant. Our findings show how motorsport companies use these ties as mechanisms for organizing their product development activities and accessing new technological developments. In going beyond cross-sectional analyses and the strong/weak tie dichotomy, we develop a processual understanding of network development and show how networks evolve through actors' looking at new opportunities (developing potential ties) and/or by suspending exchange with others that are redundant (maintaining latent ties).

Second, this paper reports and evaluates firms' strategic actions and contributes to research on "agency" in networks, especially with regard to search activities intended to promote network diversity. Organizational theorists have shown that future tie formation is largely determined by past ties and that organizations display a strong tendency toward forming ties with the same partners or with their partner's partners (Baum et al. 2005, Gulati and Gargiulo 1999, Sorenson and Stuart 2001, Zaheer and Soda 2009). Hence, existing research predicts that networks tend to evolve endogenously (Rosenkopf and Padula 2008) and remain locked into a pattern that generates increasingly closed circles of interaction and redundancy. Although the European motorsport industry follows this pattern of development to a certain extent, the findings also show that motorsport companies deviate from this path dependency and take strategic action in two substantive ways: (1) by forming new ties with distant or heterogeneous partners, and (2) by temporarily suspending exchange with existing partners. By engaging in these purposive actions, firms both strengthen and weaken ties in order to promote network optimality in terms of knowledge flows. Motorsport companies form, suspend, or dissolve network links in ways that alter the network structure, but this should not be taken to imply they are hyperrational actors endowed with full information about network structures and capable of determining them. Indeed, serendipity and casual encounters also play a vital role in the evolution of network structures. Our findings complement other work on search activities, and in particular, this paper advances understanding of the nature and purpose of search and illuminates the factors that promote the formation of distant ties. These search activities can take four forms that vary in terms of the extent to which they are personal or organizational, as well as the degree to which they are informal and serendipitous or strategic and targeted. Factors such as intense competition and the rapid obsolescence of the technologies in use play an important role in affecting actors' strategic choices over the search for new partners or the renewal of past ties. The evidence shows that motorsport companies display a preference for multiconnectivity (Powell et al. 2005), pursuing multiple independent paths and increasing the diversity of the knowledge reached.
Third, in developing this extended conceptualization of types of tie and incorporating strategic action, this paper sheds much-needed light on how the challenges of network overload and redundancy can be addressed. As has been reported elsewhere, the strengthening of ties through repeated exchange with existing partners makes knowledge flows in the network increasingly redundant (Maurer and Ebers 2006). This redundancy is further exacerbated by aspects of the search activities by organizations in their quest for novel technological developments (Gulati et al. 2012) and the increasing number of ties that are accumulated. As a way to counteract this process, firms temporarily suspend exchange through those relationships that offer limited current contributions or that have become less attractive for various reasons. These latent ties may remain part of the network in a dormant state for considerable periods of time. The management and retention of these latent connections, however, rests largely on the existence and endurance of informal and personal ties. These individual-level ties play an important role in the reactivation of organization-level ties, and their demise may herald further decay in the relationship. Here, the evidence supports and further extends the work of Shipilov and $\mathrm{Li}$ (2012) on the value of interpersonal ties.

Our findings offer important insights into the practical problems of network dynamics and how firms seek to overcome them. We show that motorsport companies prefer to renew past latent relationships rather than to forge new ties ex novo when existing partners exhibit unique expertise, high reliability, and quality of work. Moreover, given their history of successful exchange, the reactivation of latent ties may provide a quicker and smoother way to handle new developments and emerging problems. Therefore, a key implication of our findings is that during periods of redundancy and overload, it is more efficient (less time and resource expensive) and more effective (shared history and understanding) to reactivate latent ties to work in new ways and/or exchange different resources rather than to forge new potential ties.

There are a number of implications of this study for future research. The data highlight the complex and dynamic nature of networks. Contrary to much of the recent literature (for example, see Dyer and Nobeoka 2000), the findings of this study suggest that strong tie networks are not necessarily best suited for dynamic environments, such as the motorsport industry, which require constant adaptation and the introduction of new technologies. As noted by Afuah (2000), a network may become so inwardly focused that it will be unable to respond to major technological innovations that develop outside. To avoid the danger of overembeddedness (Uzzi 1997), motorsport companies not only maintain a number of arm's-length connections but also engage in the search for potential partners and suspend exchange with 
current ties. This raises the question of how context specific the findings of the current study are. Future research in other sectors would add to the findings presented here.

Our research complements the observations of Gulati et al. (2012) by unpacking and evaluating the stages and processes of relationship formation, suspension, and decay, but it also suggests that strategic action can increase the innovativeness and vitality of a network and stave off decline (see Gulati et al. 2012). Further research on the strategic actions of network participants would extend our understanding of these phenomena. Notwithstanding the opportunity for strategic action, the evolution of any network will be emergent, and its specific features are informed by the extent to which latent and potential ties, as well as strong and weak ties, are present. These structural features of networks and their implications are worthy of further research and offer the prospect of extending our understanding of the coevolution of network structures and knowledge flows - that is, the interrelationship between a network's structure and processes and the creation and flow of knowledge across that network. The elaboration of types of tie and stages of tie development provided in this paper allow for a more sophisticated assessment of the relationships between network density, individual tie strength, and knowledge creation (see McFadyen et al. 2009). For example, do networks with high levels of latency respond more rapidly and successfully to discontinuous technological innovations? Do networks with high numbers of potential ties remain less dense over time, and what effects do these ties have on knowledge creation?

The qualitative approach used to explore issues of tie dynamics and actors' strategic orientation in relation to knowledge transfer and creation was appropriate for this exploratory study and provided rich descriptions of how motorsport companies operate and act at the network level. In particular, the use of interviews and the vast amount of background information about the motorsport industry provided a deep understanding of how different network ties are formed and how motorsport companies use them. A first step in developing the robustness and analytical value of conceptions of potential and latent ties would be to subject these to testing through survey methods. This process would involve developing the dimensions of these ties that might then be evaluated through quantitative data analyses. Indeed, the research raises a number of specific issues worthy of further empirical evaluation through both quantitative and further longitudinal qualitative research: How do actors' logics of attachment, orientations to action, and perceptions of the potential value of developing closer relationships inform the prospects of potential ties? What is the relationship between types of partners (as outlined in Table 2), the scarcity and value of knowledge, and the nature of tie development? What is the relative influence of strategic orientations, industry structures, and market conditions on perceived knowledge needs and thus search activities? How do proactive and reactive search activities differ in the way they identify potential ties and facilitate the prospects of tie development? What are the interrelationships between the ties of individual actors and latent and potential ties at the interorganizational level? Further research on these issues could provide better understanding of the dynamics and operations of networks.

\section{Acknowledgments}

The authors acknowledge financial support from the UK's Economic and Social Research Council/Engineering and Physical Sciences Research Council (ESRC/EPSRC) Advanced Institute of Management Research [Grant ESRC RES-331-250014]. They are also grateful to Gautam Ahuja and the two anonymous reviewers for thoughtful comments throughout the review process.

\section{Endnote}

${ }^{1}$ Strong and weak ties have been treated both as categorical types and as ends of a continuum in the literature. In abstract ideal-typical terms, we consider them discrete types; they are qualitatively different forms of relationship. This is consistent with the approach of Danermark et al., who comment that "you cannot talk about more or less interaction, but about different types of interaction" before referring to the philosopher Henri Bergson's observation that "a great joy is not more than a little joy; it is a different kind of joy" (2002, p. 174).

\section{References}

Afuah, A. 2000. How much do your co-opetitors' capabilities matter in the face of technological change? Strategic Management J. 21(2) 397-404.

Ahuja, G. 2000. Collaboration networks, structural holes, and innovation: A longitudinal study. Admin. Sci. Quart. 45(3) 425-455.

Allen, T. J. 1977. Managing the Flow of Technology: Technology Transfer and the Dissemination of Technological Information Within the R\&D Organization. MIT Press, Cambridge, MA.

Baker, W. E., R. R. Faulkner, G. A. Fisher. 1998. Hazards of the market: The continuity and dissolution of interorganizational market relationships. Amer. Sociol. Rev. 63(2) 147-177.

Barabási, A.-L., R. Albert. 1999. Emergence of scaling in random networks. Science 286(5439) 509-512.

Baum, J. A. C., T. J. Rowley, A. V. Shipilov, Y. Chuang. 2005. Dancing with strangers: Aspiration performance and the search for underwriting syndicate partners. Admin. Sci. Quart. 50(4) 536-575.

Biggart, N. W., R. Delbridge. 2004. Systems of exchange. Acad. Management Rev. 29(1) 28-49.

Birkinshaw, J., J. Bessant, R. Delbridge. 2007. Finding, forming and performing: Creating new networks for discontinuous innovation. Calif. Management Rev. 49(3) 67-84.

Breiger, R. L. 1974. The duality of persons and groups. Soc. Forces 53(2) 181-190.

Burt, R. 1992. Structural holes: The social structure of competition. N. Nohria, R. Eccles, eds. Networks and Organizations: Structure, Form and Action. Harvard Business School Press, Boston, 57-91. 
Burt, R. S. 2000a. Decay functions. Soc. Networks 22(1) 1-28.

Burt, R. S. 2000b. The network structure of social capital. R. I. Sutton, B. M. Staw, eds. Research in Organizational Behaviour, Vol. 22. Elsevier/JAI, New York, 345-423.

Burt, R. S. 2001. Structural holes versus network closure as social capital. N. Lin, K. S. Cook, R. Burt, eds. Social Capital: Theory and Research. Aldine de Gruyter, Berlin, 201-247.

Burt, R. S. 2004. Structural holes and good ideas. Amer. J. Sociol. 110(2) 349-399.

Coffey, A., P. Atkinson. 1996. Making Sense of Qualitative Data. Sage, Thousand Oaks, CA.

Coleman, J. S. 1988. Social capital in the creation of human capital. Amer. J. Sociol. 94(Supplement) S95-S120.

Danermark, B., M. Ekstrom, L. Jakobsen, J. Karlsson. 2002. Explaining Society: Critical Realism in the Social Sciences. Routledge, London.

Dhanaraj, C., A. Parkhe. 2006. Orchestrating innovation networks. Acad. Management Rev. 30(3) 659-669.

DiMaggio, P. J., W. W. Powell. 1983. The iron cage revisited: Institutional isomorphism and collective rationality in organizational fields. Amer. Sociol. Rev. 48(2) 147-160.

Dyer, J. H., K. Nobeoka. 2000. Creating and managing a highperformance knowledge-sharing network: The Toyota case. Strategic Management J. 21(3) 345-367.

Dyer, J. H., H. Singh. 1998. The relational view: Cooperative strategy and sources of interorganizational competitive advantage. Acad. Management Rev. 23(4) 660-679.

Dyer J. H., D. S. Cho, W. Chu. 1998. Strategic supplier segmentation: The next "best practice" in supply chain management. Calif. Management Rev. 40(2) 57-77.

Eisenhardt, K. M. 1989. Building theories from case study research. Acad. Management Rev. 14(4) 532-550.

Elfring, T., W. Hulsink. 2007. Networking by entrepreneurs: Patterns of tie-formation in emerging organizations. Organ. Stud. 28(12) 1849-1872.

Faems, D., M. Janssens, B. van Looy. 2007. The initiation and evolution of interfirm knowledge transfer in $R \& D$ relationships. Organ. Stud. 28(11) 1699-1728.

Faulkner, R. R. 1983. Music on Demand: Composer and Careers in the Hollywood Film Industry. Transaction Books, New Brunswick, NJ.

Fichman, M., D. A. Levinthal. 1991. Honeymoons and the liability of adolescence: A new perspective on duration dependence in social and organizational relationships. Acad. Management Rev. 16(2) 442-468.

Gargiulo, M., M. Benassi. 1999. The dark side of social capital. R. T. A. J. Leenders, S. M. Gabbay, eds. Corporate Social Capital and Liability. Kluwer Academic Publishers, Boston, 298-322.

Granovetter, M. S. 1973. The strength of weak ties. Amer. J. Sociol. 78(6) 1360-1380.

Granovetter, M. S. 1985. Economic action and social structure: The problem of embeddedness. Amer. J. Sociol. 91(3) 481-510.

Granovetter, M. S. 1992. Problems of explanation in economic sociology. N. Nohria, R. Eccles, eds. Networks and Organizations. Harvard Business Press, Boston, 25-26.

Gulati, R. 1995. Familiarity breeds trust? The implications of repeated ties. Acad. Management J. 38(1) 85-112.

Gulati, R., M. Gargiulo. 1999. Where do interorganizational networks come from? Amer. J. Sociol. 104(5) 1439-1493.
Gulati, R., M. Sytch, A. Tatarynowicz. 2012. The rise and fall of small worlds: Exploring the dynamics of social structure. Organ. Sci. 23(2) 449-471.

Hansen, M. T. 1999. The search-transfer problem: The role of weak ties in sharing knowledge across organizational sub-units. Admin. Sci. Quart. 44(1) 82-111.

Ibarra, H. 1992. Structural alignments, individual strategies, and managerial action: Elements toward a network theory of getting things done. N. Nohria, R. Eccles, eds. Networks and Organizations. Harvard Business Press, Boston, 156-189.

Inkpen, A. C., E. W. K. Tsang. 2005. Social capital, networks, and knowledge transfer. Acad. Management Rev. 30(1) 146-165.

Jenkins, M., S. Floyd. 2001. Trajectories in the evolution of technology: A multi-level study of competition in Formula One racing. Organ. Stud. 22(6) 945-969.

Kogut, B., U. Zander. 1996. What firms do? Coordination, identity, and learning. Organ. Sci. 7(5) 502-518.

Krackhardt, D. 1992. The strength of strong ties: The importance of philos in organizations. N. Nohria, R. G. Eccles, eds. Network and Organizations: Structure, Form, and Action. Harvard Business Press, Boston, 216-239.

Larson, A. 1992. Network dyads in entrepreneurial settings: A study of the governance of exchange relationships. Admin. Sci. Quart. 37(1) 76-104

Levin, D. Z., R. Cross. 2004. The strength of weak ties you can trust: The mediating role of trust in effective knowledge transfer. Management Sci. 50(11) 1477-1490.

Levinthal, D. A., M. Fichman. 1988. Dynamics of interorganizational attachments: Auditor-client relationships. Admin. Sci. Quart. 33(3) 345-369.

Lincoln, Y. S., E. G. Guba. 1985. Naturalistic Inquiry. Sage, Newbury Park, CA.

Marsden, P. V., K. E. Campbell. 1984. Measuring tie strength. Soc. Forces 63(2) 482-501.

Maurer, I., M. Ebers. 2006. Dynamics of social capital and their performance implications: Lessons from biotechnology start-ups. Admin. Sci. Quart. 51(2) 262-292.

McEvily, B., A. Zaheer. 1999. Bridging ties: A source of firm heterogeneity in comparative capabilities. Strategic Management J. 20(12) 1133-1156.

McFadyen, M. A., M. Semadeni, A. Cannella Jr. 2009. Value of strong ties to disconnected others: Examining knowledge creation in biomedicine. Organ. Sci. 20(3) 552-564.

McPherson, J. M., L. Smith-Lovin. 1987. Homophily in voluntary organizations: Status distance and the composition of face-toface groups. Amer. Sociol. Rev. 52(3) 370-379.

Muthusamy, S. K., M. A. White. 2005. Learning and knowledge transfer in strategic alliances: A social exchange view. Organ. Stud. 26(3) 415-441.

Nahapiet, J., S. Ghoshal. 1998. Social capital, intellectual capital, and organizational advantage. Acad. Management Rev. 23(2) 242-266.

Nooteboom, B. 2000. Learning and Innovation in Organizations and Economies. Oxford University Press, Oxford, UK.

Obstfeld, D. 2005. Social networks, the tertius iungens orientation, and involvement in innovation. Admin. Sci. Quart. 50(1) $100-130$. 
Owen-Smith, J., W. W. Powell. 2003. The expanding role of university patenting in the life sciences: Assessing the importance of experience and connectivity. Res. Policy 32(9) $1695-1711$.

Parkhe, A., S. Wasserman, D. Ralston. 2006. New frontiers in network theory development. Acad. Management Rev. 31(3) 560-568.

Parsons, T. 1968. The Structure of Social Action, Vol. 2. Free Press, Weber, NY.

Patton, M. Q. 1990. Qualitative Evaluation and Research Methods. Sage, Newbury Park, CA.

Pfeffer, J., G. R. Salancik. 1978. The External Control of Organizations: A Resource Dependence Perspective. Harper \& Row, New York

Podolny, J. M. 1994. Market uncertainty and the social character of economic exchange. Admin. Sci. Quart. 39(3) 458-483.

Powell, W. W. 1990. Neither market nor hierarchy: Network forms of organization. B. M. Staw, L. L. Cummings, eds. Research in Organization Behavior, Vol. 12. JAI Press, Greenwich, CT, 295-336.

Powell, W. W. 1998. Learning from collaboration. Knowledge and networks in the biotechnology and pharmaceutical industries. Calif. Management Rev. 40(3) 228-240.

Powell, W. W., K. W. Koput, L. Smith-Doerr. 1996. Interorganizational collaboration and the locus of innovation: Networks of learning in biotechnology. Admin. Sci. Quart. 41(1) 116-145.

Powell, W., D. White, K. Koput, J. Owen-Smith. 2005. Network dynamics and field evolution: The growth of interorganizational collaboration in the life sciences. Amer. J. Sociol. 110(4) $1132-1205$.

Pye, M. 2001. Autosport directory 2001. Autosport, http://www .autosport.com/directory/.

Reagans, R., B. McEvily. 2003. Network structure and knowledge transfer: The effects of cohesion and range. Admin. Sci. Quart. 48(2) 240-267.

Ring, P. S., A. H. van de Ven. 1992. Structuring cooperative relationships between organizations. Strategic Management J. 13(7) 483-498.

Rosenkopf, L., G. Padula. 2008. Investigating the microstructure of network evolution: Alliance formation in the mobile communications industry. Organ. Sci. 19(5) 669-687.

Rowley, T. J., D. Behrens, D. Krackhardt. 2000. Redundant governance structures: An analysis of structural and relational embeddedness in the steel and semiconductor industries. Strategic Management J. 21(3) 369-386.

Salancik, G. R. 1995. WANTED: A good network theory of organization. Admin. Sci. Quart. 40(2) 345-349.

Seabright, M., D. Levinthal, M. Fichman. 1992. The role of individual attachments in interorganizational relationships. Acad. Management J. 35(1) 122-160.

Shipilov, A. V., S. X. Li. 2012. The missing link: The effect of customers on the formation of relationships among producers in the multiplex triads. Organ. Sci. 23(2) 472-491.

Sorenson, O., T. E. Stuart. 2001. Syndication networks and the spatial distribution of venture capital investments. Amer. J. Sociol. 106(6) 1546-1588.
Sorenson, O., T. E. Stuart. 2008. Bringing the context back in: Settings and the search for syndicate partners in venture capital investment networks. Admin. Sci. Quart. 53(2) 266-294.

Starkey, K., C. Barnatt, S. Tempest. 2000. Beyond networks and hierarchies: Latent organizations in the U.K. television industry. Organ. Sci. 11(3) 299-305.

Steier, L., R. Greenwood. 2000. Entrepreneurship and the evolution of angel financial networks. Organ. Stud. 21(1) 163-192.

Strauss, A., J. Corbin. 1990. Basics of Qualitative Research: Grounded Theory Procedures and Techniques. Sage, Newbury Park, CA.

Todeva, E. 2006. Business Networks: Strategy and Structure. Routledge, London.

Tsai, W., S. Ghoshal. 1998. Social capital and value creation: An empirical study of intrafirm networks. Acad. Management $J$. 41(4) 464-476.

Uzzi, B. 1996. The sources and consequences of embeddedness for the economic performance of organizations: The network effect. Amer. Sociol. Rev. 61(4) 674-698.

Uzzi, B. 1997. Social structure and competition in interfirm networks: The paradox of embeddedness. Admin. Sci. Quart. 42(1) 35-67.

Uzzi, B. 1999. Embeddedness in the making of financial capital: How social relations and networks benefit firms seeking financing. Amer. Sociol. Rev. 64(August) 481-505.

Uzzi, B., J. J. Gillespie. 2002. Knowledge spillover in corporate financing networks: Embeddedness and the firm's debt performance. Strategic Management J. 23(7) 595-618.

Watts, D. J., S. H. Strogatz. 1998. Collective dynamics of "smallworld" networks. Nature 393(6684) 440-442.

Weick, K. E. 1976. Educational organizations as loosely coupled systems. Admin. Sci. Quart. 21(1) 1-19.

Williamson, O. E. 1985. The Economic Institutions of Capitalism. Free Press, New York.

Zaheer, A., G. Soda. 2009. Network evolution: The origins of structural holes. Admin. Sci. Quart. 54(1) 1-31.

Zahra, S. A., R. D. Ireland, M. A. Hitt. 2000. International expansion by new venture firms: International diversity, mode of market entry, technological learning and performance. Acad. Management J. 43(5) 925-950.

Francesca Mariotti is an honorary research fellow at Cardiff Business School, Cardiff University, United Kingdom. Her research interests include the dynamics and evolution of interfirm networks and the management of innovation. She is a research associate of the Advanced Institute of Management Research.

Rick Delbridge is an associate dean (Research) and professor of organizational analysis at Cardiff Business School, Cardiff University, United Kingdom. His research interests include managing innovation, organizing work, and employment relations. He is an associate editor of Organization, a senior fellow of the Advanced Institute of Management Research, and an academician of the Academy of Social Sciences. 